\title{
Wild populations of malaria vectors can mate both inside and outside human dwellings
}

\author{
Ismail H. Nambunga ${ }^{1,2^{*+}}$, Betwel J. Msugupakulya ${ }^{1,3+}$, Emmanuel E. Hape ${ }^{1,2}$, Issa H. Mshani ${ }^{1,2}$, \\ Najat F. Kahamba1,2,3, Gustav Mkandawile', Daniel M. Mabula', Rukiyah M. Njalambaha', \\ Emmanuel W. Kaindoa ${ }^{1,3,4}$, Letus L. Muyaga', Marie R. G. Hermy ${ }^{5}$, Frederic Tripet ${ }^{6}$, Heather M. Ferguson ${ }^{1,2}$, \\ Halfan S. Ngowo ${ }^{1,2}$ and Fredros O. Okumu 1,2,3,4*
}

\begin{abstract}
Background: Wild populations of Anopheles mosquitoes are generally thought to mate outdoors in swarms, although once colonized, they also mate readily inside laboratory cages. This study investigated whether the malaria vectors Anopheles funestus and Anopheles arabiensis can also naturally mate inside human dwellings.

Method: Mosquitoes were sampled from three volunteer-occupied experimental huts in a rural Tanzanian village at 6:00 p.m. each evening, after which the huts were completely sealed and sampling was repeated at 11:00 p.m and 6 a.m. the next morning to compare the proportions of inseminated females. Similarly timed collections were done inside local unsealed village houses. Lastly, wild-caught larvae and pupae were introduced inside or outside experimental huts constructed inside two semi-field screened chambers. The huts were then sealed and fitted with exit traps, allowing mosquito egress but not entry. Mating was assessed in subsequent days by sampling and dissecting emergent adults caught indoors, outdoors and in exit traps.

Results: Proportions of inseminated females inside the experimental huts in the village increased from approximately $60 \%$ at 6 p.m. to approximately $90 \%$ the following morning despite no new mosquitoes entering the huts after 6 p.m. Insemination in the local homes increased from approximately $78 \%$ to approximately $93 \%$ over the same time points. In the semi-field observations of wild-caught captive mosquitoes, the proportions of inseminated An. funestus were 20.9\% (95\% confidence interval [Cl]: \pm 2.8 ) outdoors, 25.2\% (95\% Cl: \pm 3.4$)$ indoors and 16.8\% ( \pm 8.3$)$ in exit traps, while the proportions of inseminated An. arabiensis were $42.3 \%(95 \% \mathrm{Cl}: \pm 5.5)$ outdoors, $47.4 \%(95 \% \mathrm{Cl}: \pm 4.7)$ indoors and $37.1 \%(\mathrm{Cl}: \pm 6.8)$ in exit traps.

Conclusion: Wild populations of An. funestus and An. arabiensis in these study villages can mate both inside and outside human dwellings. Most of the mating clearly happens before the mosquitoes enter houses, but additional mating happens indoors. The ecological significance of such indoor mating remains to be determined. The observed insemination inside the experimental huts fitted with exit traps and in the unsealed village houses suggests that the indoor mating happens voluntarily even under unrestricted egress. These findings may inspire improved vector control, such as by targeting males indoors, and potentially inform alternative methods for colonizing strongly eurygamic Anopheles species (e.g. An. funestus) inside laboratories or semi-field chambers.
\end{abstract}

\footnotetext{
*Correspondence: inambunga@ihi.or.tz; fredros@ihi.or.tz

${ }^{\dagger}$ Ismail H. Nambunga and Betwel J. Msugupakulya contributed equally to this work

${ }^{1}$ Environmental Health and Ecological Sciences Department, Ifakara Health Institute, P.O. Box 53, Ifakara, Tanzania

Full list of author information is available at the end of the article
} permits use, sharing, adaptation, distribution and reproduction in any medium or format, as long as you give appropriate credit to the original author(s) and the source, provide a link to the Creative Commons licence, and indicate if changes were made. The images or other third party material in this article are included in the article's Creative Commons licence, unless indicated otherwise in a credit line to the material. If material is not included in the article's Creative Commons licence and your intended use is not permitted by statutory regulation or exceeds the permitted use, you will need to obtain permission directly from the copyright holder. To view a copy of this licence, visit http://creativecommons.org/licenses/by/4.0/. The Creative Commons Public Domain Dedication waiver (http://creativeco mmons.org/publicdomain/zero/1.0/) applies to the data made available in this article, unless otherwise stated in a credit line to the data. 
Keywords: Mosquito mating, Anopheles funestus, Anopheles arabiensis, Eurygamic species, Malaria, Tanzania

\section{Background}

Members of the Anopheles gambiae complex and Anopheles funestus group mediate the majority of malaria parasite infections in many parts of sub-Saharan Africa [1-4], where $94 \%$ of all malaria deaths and $93 \%$ of all cases occurred in 2019 [5]. Countries in this region rely mostly on the use of insecticide-treated nets (ITNs), indoor residual spraying (IRS), as well as effective case management and behavior change communication strategies to control malaria $[6,7]$. These interventions have played a major role in reducing the burden of malaria in the past decades, with vector control interventions contributing to the majority of the success [8-11]. Unfortunately, recent evidence indicates that progress against malaria is plateauing and that gains may be lost [6].

While the major vector control tools, ITNs and IRS, primarily target mosquitoes that bite and rest indoors [12-15], it is widely accepted that additional tools targeting other aspects of the mosquito life-cycle will be important to further drive progress against malaria [16-18]. One of the opportunities for designing new approaches or optimizing current ones is through an improved understanding of the reproductive behaviors of mosquitoes. For example, a greater understanding of mosquito swarming and mating can enable improved targeting of male mosquitoes [19]. Technologies such as sterile insect techniques (SIT) [20], genetic modification of mosquitoes (GMM) [21] and space spraying of mosquito swarms $[19,22]$ are some of the interventions that exploit the mating behavior of mosquitoes. In Burkina Faso, space spraying of mosquito swarms reduced mosquito populations by up to $80 \%$ in the intervention village [19].

Both GMM and SIT have been explored to varying degrees for impact on different insect and pest populations [23-25]. Their successes can be greatly improved if the behaviors of both male and female insects are investigated and exploited. In addition, some of the complementary tools currently being evaluated, notably attractive targeted sugar baits (ATSBs) [26-28], could also be improved by possibly targeting both male and female mosquitoes inside and outside houses.

Like many other diptera, mosquito mating occurs mostly in swarms outside homes [29], where groups of male mosquitoes, usually of the same species, aggregate at specific times and places [30]. Several minutes after mosquito swarming begins, females join the swarm to seek a mate and leave in copula [22]. Mosquito swarming is thought to be mediated by the circadian rhythm of male mosquitoes [31,32] and the presence of specific environmental markers in a particular locality [33, 34]. Recent evidence shows that this behavior might also be mediated by specific aggregation pheromones produced by male mosquitoes [35].

While Anopheles swarms often occur outdoors in open spaces at dusk [36-38], during recent collections of resting mosquitoes in south-eastern Tanzania, large numbers of male Anopheles were observed resting inside houses at dusk, at a time the males are supposedly in swarms (B) Msugupakulya, unpublished). In a separate study, swarms of An. funestus were observed very close to human houses (often at the level of eaves) [36], unlike those of An. arabiensis which tended to occur mostly at the edge of the villages [33]. An experimental hut observation in west Africa found that the daily insemination rates were approximately $5 \%$ higher in exit traps than entry traps, implying that some limited mating could occur indoors independent of outdoor swarms [39].

In addition to advancing vector control, a greater understanding of Anopheles mating could also improve capabilities for colonizing some of the species that are otherwise difficult to rear inside laboratories. One particular example is An. funestus, which dominates malaria transmission in several east and southern Africa zones [3, 40-43], yet there have been only two successful laboratory colonies using field-collected material from Mozambique and Angola [44]. Recent evidence from attempted colonization has highlighted mating as one of the bottlenecks to colonization [45]. Studying the conditions of successful mating both outdoors in the wild and in captivity could improve rearing of these and other eurygamic mosquito species.

In the present study, we therefore, investigated indoor and outdoor insemination rates in major malaria vectors (An. funestus and An. arabiensis) under both field and semi-field conditions, to inform new opportunities for improving their control and also to improve efforts to colonize various Anopheles species for laboratory studies.

\section{Methods \\ Study sites}

This study was implemented in four phases in the field and semi-field environments. The field studies were conducted in south-eastern Tanzania, in five villages located in Ulanga district, namely Kivukoni $\left(-8.2021^{\circ} \mathrm{S}\right.$, $\left.36.6961^{\circ} \mathrm{E}\right)$, Minepa $\left(-8.1455^{\circ} \mathrm{S}, 36.4244^{\circ} \mathrm{E}\right)$, Tulizamoyo $\left(-8.3669^{\circ} \mathrm{S}, 36.7336^{\circ} \mathrm{E}\right)$, Kilisa $\left(-8.3721^{\circ} \mathrm{S}, 36.5584^{\circ} \mathrm{E}\right)$ and Ruaha $\left(-8.9068^{\circ} \mathrm{S}, 36.7185^{\circ} \mathrm{E}\right)$, and in two villages located in Kilombero district, Sululu $\left(-7.9973^{\circ} \mathrm{S}, 36.8317^{\circ} \mathrm{E}\right)$ and 
Ikwambi $\left(-7.9833^{\circ} \mathrm{S}, 36.8184^{\circ} \mathrm{E}\right)$ (Fig. 1). The principal malaria vectors in the area are An. arabiensis, and $A n$. funestus [40, 41, 46, 47]. Several other anophelines and some culicine mosquito species are also present in the study area. The semi-field experiments were conducted inside large screen house compartments at the Mosquito City facility maintained by Ifakara Health Institute in Kining'ina village $\left(-8.1080^{\circ} \mathrm{S}, 36.6668^{\circ} \mathrm{E}\right)$ in Kilombero district. These semi-field systems were designed to mimic the natural environment, and have built-in experimental huts for controlled mosquito studies [48].

\section{Study procedures}

The four study phases included: (i) assessment of indoor resting densities of male Anopheles mosquitoes relative to females in different house types; (ii) observations of insemination status of wild-caught female mosquitoes at different times of night inside volunteer-occupied experimental huts in the village; (iii) field observations to assess whether wild mosquitoes' mate before or after entering local houses occupied by residents; and (iv) semi-field observations of wild-caught mosquitoes inside large screen house chambers to verify and quantify the insemination rates inside and outside experimental huts under controlled settings.

\section{Observations of male mosquitoes resting inside different types of houses}

Mosquito collections were conducted in 80 houses in the four study villages (Fig. 1), targeting four common house

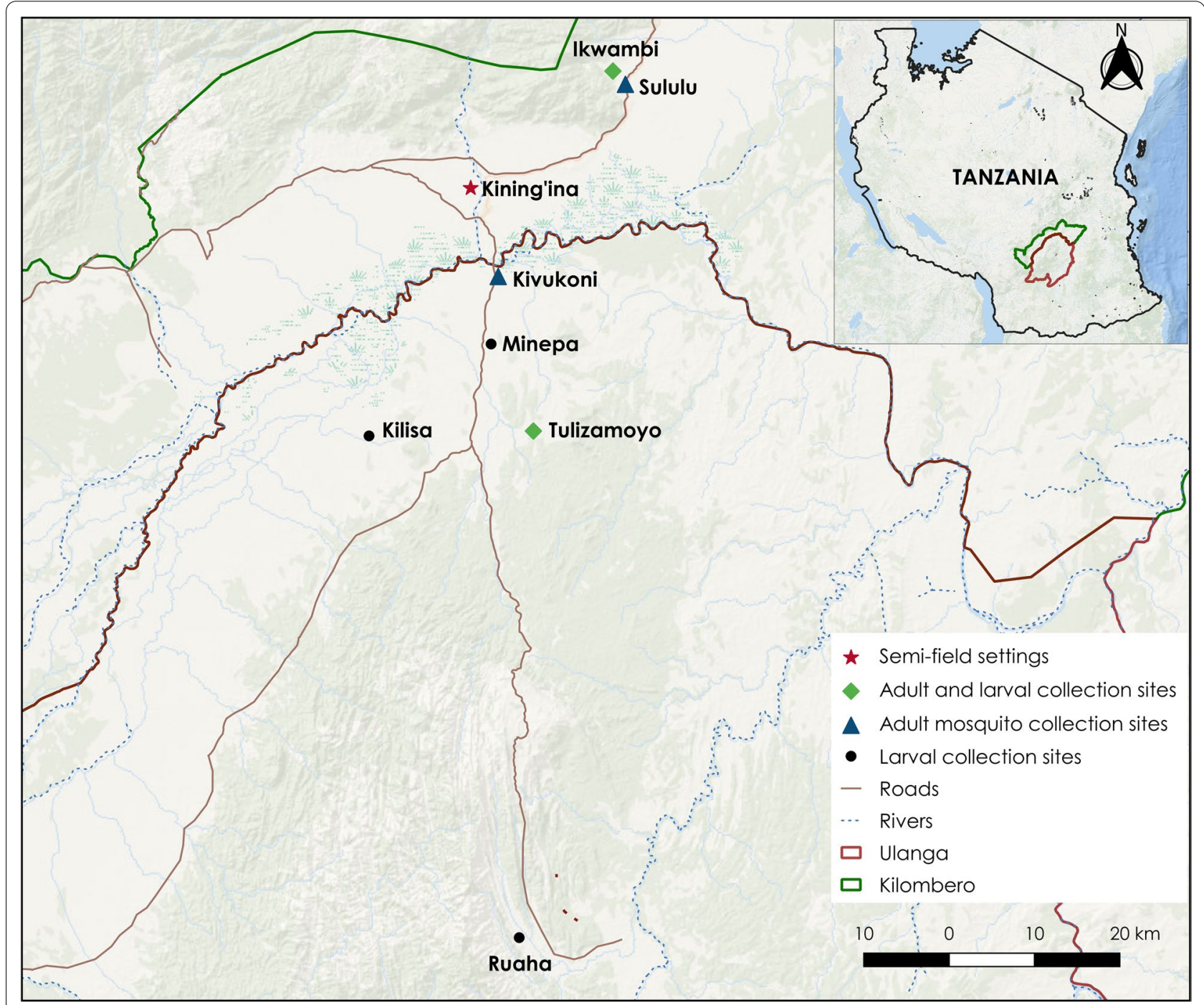

Fig. 1 Map of Kilombero and Ulanga districts showing the locations where experiments were conducted 
types, namely: (i) 20 houses with thatched roofs and mud walls; (ii) 20 houses with thatched roofs and unplastered brick walls; (iii) 20 houses with metal roofs and unplastered brick walls; and (iv) 20 houses with metal roofs and plastered brick walls. Inside the houses, mosquitoes were collected from all potential resting surfaces using Prokopack aspirators (John W. Hock Company, Gainesville, FL, USA) to obtain total numbers of mosquitoes resting inside each house. Initially, mosquito collections were conducted only in the morning, separated into early morning (7-9 a.m.) and late morning (9-12 a.m.) collections, but additional collections were subsequently performed in the early evening (6-20 p.m.) and late at night (12 midnight-2 a.m.), as previously described by Msugupakulya et al.[49].

\section{Observations of insemination in wild mosquitoes caught inside volunteer-occupied experimental huts}

This experiment was conducted in Tulizamoyo village using three volunteer-occupied experimental huts constructed for the study, as shown in Fig. 2. The same volunteers were used throughout the study, and each volunteer was allocated his own sleeping room (always the same room) for the duration of the study. These tent-styled huts consisted of easy-to-seal eave spaces and screened windows, and were located near other village houses used by residents (Fig. 2). During the study, the eave spaces remained open during the daytime (7 a.m. to 6 p.m.) to allow mosquito entry, and were closed at 6 p.m. Trained volunteers entered each experimental hut just before the huts were closed at 6 p.m. and collected mosquitoes using a Prokopack aspirator from multiple indoor surfaces for a total of $5 \mathrm{~min}$ each time. Without re-opening the huts after their closure at
6 p.m., follow-up collections were done at 11 p.m. and again at 6 a.m. the following morning, after which the huts were then re-opened. At each of these time points, the sampling was done at multiple locations inside the huts. In between collections, the volunteers slept under untreated nets inside the huts.

We hypothesized that the proportions of inseminated females would stay either similar (if no additional mating happened indoors after hut closures at 6 p.m.) or increase (if there was additional mating after 6 p.m.). Collected mosquitoes were kept in labeled cups and transferred to the laboratory for morphological identification and assessment of their insemination status.

The sampled female mosquitoes were initially identified using morphological keys for Afrotropical Anopheles mosquitoes [50, 51]. Anopheles funestus and An. arabiensis were dissected under a stereomicroscope. The seventh segment of immobilized mosquitoes was dissected to extract spermathecae, which were examined under a light microscope with a $10 \times$ magnification lens for insemination status. Female mosquitoes with filled long threads of coiled brown spermatheca were considered to be inseminated while those with clear and non-striated spermathecae were considered to be non-inseminated [52]. This study was conducted for 14 consecutive nights in the first round.

After the first round, the experiment was repeated for another 10 consecutive nights using the same procedures as described above, with the exception that all mosquitoes were immobilized by freezing in portable cooler boxes immediately after collection to avoid any possible mating that could happen inside the holding cups.

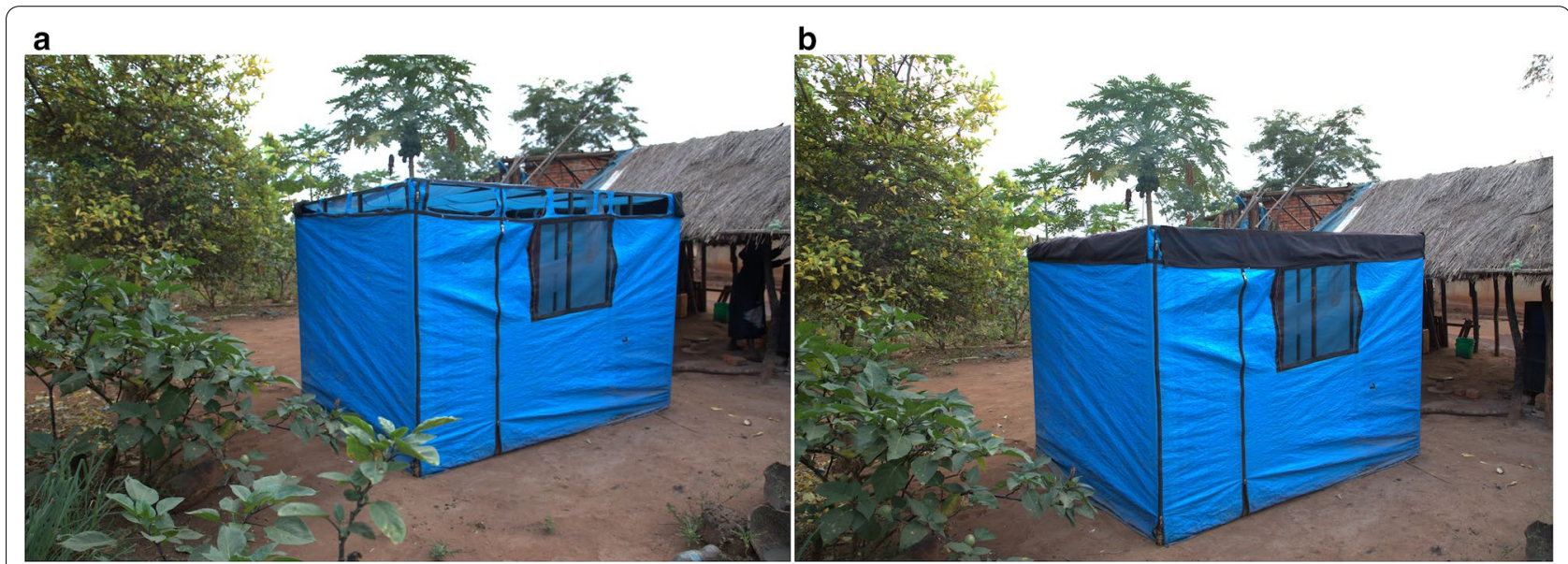

Fig. 2 Experimental huts where mosquitoes were collected for assessment of insemination status of mosquitoes at different times points during the evening, night and following morning. a Eave spaces open to allow mosquito entry, $\mathbf{b}$ eave spaces closed for collection 


\section{Observation of insemination in wild female mosquitoes caught from local houses in the study village}

An additional experiment to assess the insemination of malaria vectors was performed for 5 nights using natural houses where people live in the study village. Three thatched-roof and three iron roof houses, all of which were occupied by residents of the villages, were used for this experiment. During this phase of the experiment, the eaves were left open to allow mosquitos to freely enter and exit the dwellings. At 6 p.m. and 11 p.m. on the same evening and at 6 a.m. the following morning, mosquitoes were collected using Prokopack aspirators and immobilized immediately in the cooler box with ice packs to prevent any potential mating activity inside the holding cups and during transportation. These wild-caught mosquitoes were then transported to the insectary, and females were assessed for their insemination status as described above.

\section{Observations of insemination in wild-caught mosquitoes maintained under semi-field conditions}

The semi-field system consisted of large multi-chambered screen houses with netting walls, enclosing villagelike ecosystems of vegetation and water puddles [48]. Each chamber $(9.6 \times 9.6 \mathrm{~m})$ had an experimental hut constructed to mimic the design of typical local houses used in rural Tanzania (Fig. 3). Three chambers were used for this study. The experimental huts in the selected chambers were completely sealed with mosquito netting on the eave spaces, but the windows were fitted with window exit traps to catch any mosquitoes attempting to exit the huts. With this design, mosquitoes inside the huts could attempt to exit (and be trapped in the window exit traps) but those outside could not enter the huts (since all eave openings were screened, doors were closed and windows were covered with the exit traps). For additional

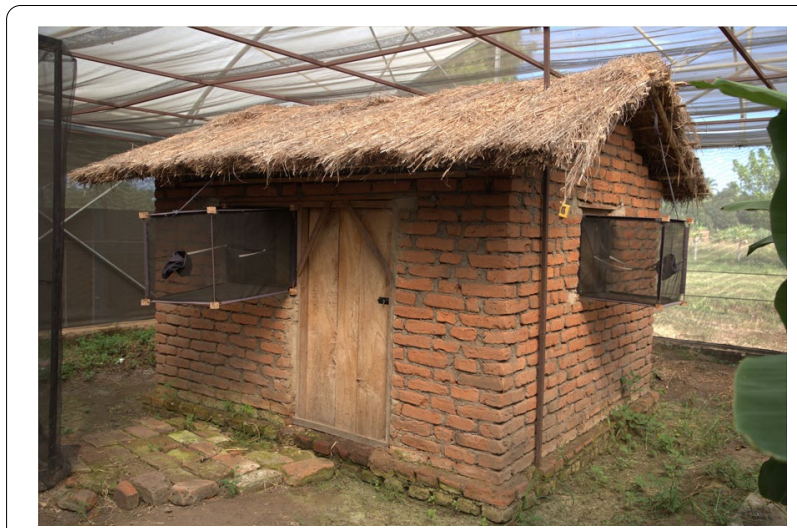

Fig. 3 Experimental hut constructed inside the semi-field chambers and fitted with window exit traps control, the doors were fitted with overlapping net curtains to prevent mosquitoes from flying in or out whenever someone entered.

Field collections of third and fourth instar Anopheles larvae were performed using a combination of standard 350-ml dippers (for small habitats) and 10-L buckets (for large habitats) to maximize densities, as previously described by Nambunga et al. [53]. The larvae were sorted, and only Anopheles larvae were used for further observations. The larvae were maintained in rearing basins and fed daily on TetraMin ${ }^{\circledR}$ fish food (Tetra, Melle, Germany) until they reached the pupae stage.

For each batch of field-collected mosquitoes, the pupae were divided into two approximately equal-sized groups, one of which was put inside the experimental hut in the semi-field chamber, and the second group placed outside the hut. No sex separation of the mosquitoes was done, so each group of pupae yielded both male and female virgins. This experimental set-up was replicated in three different semi-field chambers, each with a similar-sized hut. The field collections were repeated weekly for 12 months, each time adding approximately half of the pupae inside and half outside the huts in each of the three chambers. Inside the experimental chambers, a 10\% glucose solution soaked in cotton wool was provided as a source of energy for the emerging mosquitos. Emerged adult mosquitoes were recaptured twice weekly from inside and outside the huts (using human landing catches) as well as in the exit traps fitted to the hut windows. The recaptured female mosquitoes were kept in labeled cups and immediately assessed for insemination by dissecting and observing the spermatheca as described above. The observations were done immediately after collections in order to minimize the likelihood of mosquitoes mating inside the collection cups.

\section{Molecular identification of An. funestus sibling species}

A subsample of An. funestus collected from the field and those emerged adults in the semi-field experiments were packed individually in microcentrifuge tubes containing silica gel. The samples were transported to the molecular laboratory at Ifakara Health Institute for sibling species identification using PCR as described by Koekemoer et al. [54].

\section{Statistical analyses}

Data were analyzed using the open-source statistical software $\mathrm{R}$ version 3.6.0 [55]. Proportions and means were used for initial descriptive statistics of mosquitoes in different categories, and mean outcomes were calculated for each explanatory variable. In the first field survey, generalized linear mixed effect models (glmer), with a negative binomial distribution to account for overdispersion with 
interaction terms (house types and collection time), were used to assess mean number and variations of male mosquitoes collected inside different house types and at different collection times, i.e. early morning (7-9 a.m.), late morning (9 a.m. to 12 noon), evening (6-8 p.m.) and late evening/early nighttime (12 midnight to 2 a.m.). Random variables included in these models were the experimental round (one round involved collecting mosquitoes in each study house until collections had been performed in all study houses in each village) and household nested within villages. Additionally, pairwise comparisons were performed using Tukey's Honestly Significant Difference test with functions provided in the multcomp packages in R software.

To compare the proportion of inseminated and noninseminated mosquitoes per time, glmer models with binomial distribution and logit functions were used. For the observations of wild mosquitoes in the village, the proportion of inseminated and non-inseminated females was modeled as a function of time of mosquito sampling, i.e. evening (6 p.m.), nighttime (11 p.m.) and early morning (6 a.m.). The sampling date and hut identifier were included as random variables in the model. For observations of wild-caught mosquitoes observed in semi-field captivity, the number of inseminated and non-inseminated females was modeled as a function of the location of mosquito recapture, i.e. inside hut, outside hut or in the window exit traps. Again, the sampling date and semi-field chamber identifiers were included as random variables. Results of the models were presented as odds ratios (OR) with 95\% confidence intervals (CI) and their associated $P$-values.

\section{Results \\ Observations of male mosquitoes resting inside different types of houses}

High densities of male mosquitoes were collected by the Prokopack trap while resting inside all house types. A total of 27,807 mosquitoes were collected indoors, comprising An. funestus, An. arabiensis, Anopheles coustani and Culex mosquitoes. Of these, 5841 were $A n$. funestus (22.4\% of which were males [ $n=1306]), 1269$ were $A n$. arabiensis $(23.0 \%$ of which were males $[n=292])$ and 49 were An. coustani 49 (only 1 of which was a male mosquito); there were 20,476 Culex mosquitoes collected (of which $40.5 \%$ were males $[n=8289])$. House type significantly influenced indoor densities of male mosquitoes, with thatched-roof houses having slightly higher densities of male Anopheles (but not Culex) mosquitoes than metal roof houses (Fig. 4a; Additional file 1: Table S1). The indoor densities of Anopheles male mosquitoes were also higher in the early- and late-morning collections than in the evening and nighttime collections (Fig. 4B; Additional file 1: Table S1).

Overall, the mean number of male An. funestus indoors varied from 0.14 (95\% CI: $0.03-0.68$ ) to 0.72 (95\% CI: $0.16-3.26)$ per house per night, while the mean number of male An. arabiensis varied from 0.02 (95\% CI: $0.01-0.13)$ to 0.21 (95\% CI: 0.05-0.56) per house per night (Additional file 1: Table S2). The results of the analysis indicate that, although the number of mosquitoes varied with house type, the interaction between house types and time of collection showed the same trend (Additional file 1: Table S2).

\section{Observations of insemination in wild mosquitoes caught inside volunteer-occupied tented huts in rural Tanzania}

The proportion of inseminated females increased significantly after the collections at 6 p.m. and was highest in the morning collections conducted at 6 a.m., even though the huts remained completely sealed from 6 p.m. to early the following morning. A total of 594 An. funestus (489 females and 105 males) and 795 An. arabiensis (647 female and 148 male) mosquitoes were collected over the first 14 nights. The mean proportion of inseminated An. funestus mosquitoes increased from $60.7 \%(95 \% \mathrm{CI}: \pm 7.2 \%)$ at the 6 p.m. collections to $79.6 \%(95 \% \mathrm{CI}: \pm 5.1 \%)$ at 11 p.m. and $92.8 \%(95 \%$ $\mathrm{CI}: \pm 3.8 \%)$ the following morning at 6 a.m. Similarly, the mean proportion of inseminated $A n$. arabiensis females increased from $60.6 \%(95 \% \mathrm{CI}: \pm 4.8 \%)$ at 6 p.m. to $80.4 \%$ (95\% CI: $\pm 4.1 \%)$ at 11 p.m. and $88.1 \%(95 \%$ $\mathrm{CI}: \pm 4.4 \%$ ) the following morning at 6 a.m. (Fig. 5a; Table 1). The glmer analysis showed that the increases were statistically significant $(P<0.001)$ (Table 1$)$.

Analysis of data from the second round of the experiment (conducted over 10 nights, during which the captured mosquitoes were immediately immobilized) revealed a similar trend of increasing proportion of insemination from 6 p.m. to 6 a.m. The mean proportion of inseminated An. funestus females increased from $25 \%(95 \% \mathrm{CI}: \pm 19.8 \%)$ at 6 p.m. to $71.4 \%(95 \%$ $\mathrm{CI}: \pm 29.1 \%)$ at 11 p.m. and $83.3 \%(95 \% \mathrm{CI}: \pm 16.3 \%)$ at 6 a.m. On the other hand, the mean proportion of $A n$. arabiensis increased from $46.1 \%(95 \% \mathrm{CI}: \pm 8 \%)$ at 6 p.m. to $72.4 \%(95 \% \mathrm{CI}: \pm 17.2 \%)$ at 11 p.m. and finally 74.6\% (95\% CI: $\pm 12.5 \%)$ at 6 a.m. (Fig. 5b; Table 1).

The male to female ratio for An. funestus and An. arabiensis caught in the experimental huts at the different collection times are also shown (Fig. 6). PCR analysis showed that of all the 50 subsamples of An. funestus collected from the field experiment, 94\% $(n=47)$ were An. funestus s.s. with the other $6 \%(n=3)$ unamplified, 


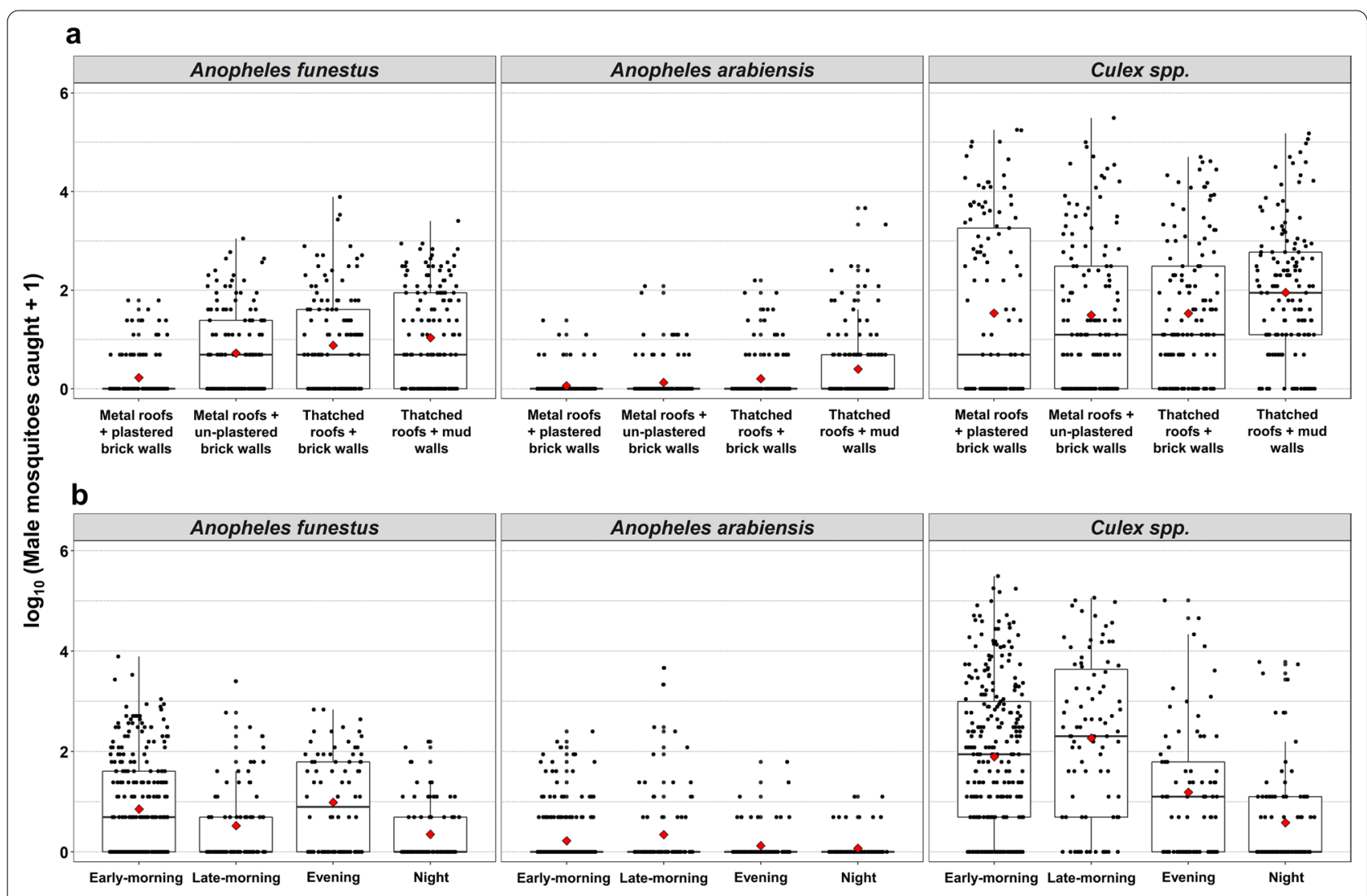

Fig. 4 Mean differences in the densities of male mosquitoes collected from different house types (a) and at the different collection time points (b)

while An. arabiensis was the only member of An. gambiae complex in the area.

\section{Observation of insemination in the wild mosquitoes caught from local houses occupied by natives in the study village}

Similar to wild mosquitoes caught inside volunteeroccupied experimental huts, the proportion of inseminated females caught from houses in the study villages increased significantly after the 6 p.m. collections and was highest in the morning collections. In total, 350 female and 64 male An. funestus and 369 female and 74 male An. arabiensis were collected over 5 nights of this experiment.

Regardless of house type, the mean proportion of inseminated An. funestus and An. arabiensis females increased overnight (Fig. 7). The mean proportion of An. funestus increased from $76.4 \%$ (95\% CI: $\pm 9.9 \%)$ at 6 p.m. to $88.8 \%$ (95\% CI: $\pm 9.9 \%$ ) at 11 p.m. to $93.3 \%$ (95\% $\mathrm{CI}: \pm 6.2 \%)$ at 6 a.m. in metal roof houses, and from $74.7 \%$ (95\% CI: $\pm 12.1 \%)$ at 6 p.m. to $82.7 \%(95 \% \mathrm{CI}: \pm 10.3 \%)$ at 11 p.m. to $96.1 \%(95 \% \mathrm{CI}: \pm 5.3 \%)$ at 6 a.m. in thatchedroof houses. For An. arabiensis, the mean proportion of insemination increased from $81.8 \%(95 \% \mathrm{CI}: \pm 10.9 \%)$ at
6 p.m. to $89.2 \%$ (95\% CI: $\pm 6.0 \%$ ) at 11 p.m. to $90.8 \%$ (95\% CI: $\pm 6.2 \%)$ at 6 a.m. in metal roof houses, and from $80 \%$ $(95 \% \mathrm{CI}: \pm 12.5 \%)$ at 6 p.m. to $89.4 \%(95 \% \mathrm{CI}: \pm 9.2 \%)$ at 11 p.m. to $91.5 \%(95 \% \mathrm{CI}: \pm 7.4 \%)$ at 6 a.m. in thatchedroof houses (Fig. 7).

In a combined analysis of the house types, a significant increase in the proportion of inseminated female Anopheles mosquitoes was observed from evening to morning. However, with $A n$. arabiensis, the difference in the proportion of inseminated mosquitoes collected between 6 p.m. and 11 p.m. was marginal (Table 1).

\section{Observations of insemination in wild-caught Anopheles mosquitoes maintained under semi-field conditions}

In the semi-field compartments where wild-caught mosquitoes were held captive either inside or outside experimental huts (Fig. 3), a total of 3241 female Anopheles mosquitoes were recaptured following multiple collections over the 12 months of the experiment. Of these, $56.6 \%(n=1833)$ were An. funestus and $43.4 \%(n=1408)$ were An. arabiensis. Overall, $25.5 \%$ of An. funestus and $45.5 \%$ of An. arabiensis female mosquitoes that were caught were inseminated. 
Table 1 Mean proportion of insemination of Anopheles funestus and An. arabiensis collected at different time points

\begin{tabular}{|c|c|c|c|c|c|c|c|c|c|}
\hline \multirow[t]{2}{*}{ Experiments } & \multirow{2}{*}{$\begin{array}{l}\text { Collection time } \\
\text { point }\end{array}$} & \multicolumn{4}{|c|}{ Anopheles funestus } & \multicolumn{4}{|c|}{ Anopheles arabiensis } \\
\hline & & $\begin{array}{l}\text { No. } \\
\text { females } \\
\text { collected }\end{array}$ & $\begin{array}{l}\text { Proportion } \\
\text { inseminated (95\% } \\
\text { Cl) }\end{array}$ & $\begin{array}{l}\text { OR }(95 \% \mathrm{Cl}) \text { for } \\
\text { insemination }\end{array}$ & $P$-value & $\begin{array}{l}\text { No. females } \\
\text { collected }\end{array}$ & $\begin{array}{l}\text { Proportion } \\
\text { inseminated (95\% } \\
\mathrm{Cl}^{\mathrm{a}}\end{array}$ & $\begin{array}{l}\text { OR }(95 \% \mathrm{Cl}) \text { for } \\
\text { insemination }\end{array}$ & \\
\hline \multirow{3}{*}{$\begin{array}{l}\text { Round } 1 \text { of studies } \\
\text { in experimental huts } \\
\text { in rural Tanzania ( } 14 \\
\text { nights) }\end{array}$} & $\begin{array}{l}\text { Evening (6:00 } \\
\text { p.m.) }\end{array}$ & 191 & $60.7 \%(53.5-67.9)$ & Reference & & 228 & $60.6 \%(55.8-65.4)$ & Reference & \\
\hline & $\begin{array}{l}\text { Night (11:00 } \\
\text { p.m.) }\end{array}$ & 175 & $79.6 \%(74.5-84.7)$ & $2.39(1.50-3.79)$ & $<0.001$ & 240 & $80.4 \%(76.3-84.5)$ & $2.54(1.69-3.83)$ & $<0.001$ \\
\hline & $\begin{array}{l}\text { Morning (6:00 } \\
\text { a.m.) }\end{array}$ & 123 & $92.8 \%(89.0-96.6)$ & $6.10(3.14-11.85)$ & $<0.001$ & 179 & $88.1 \%(83.7-92.5)$ & $4.91(2.90-8.31)$ & $<0.001$ \\
\hline \multirow{3}{*}{$\begin{array}{l}\text { Round } 2 \text { of studies in } \\
\text { experimental huts } \\
\text { in rural Tanzania ( } 10 \\
\text { nights) }\end{array}$} & $\begin{array}{l}\text { Evening (6:00 } \\
\text { p.m.) }\end{array}$ & 17 & $25 \%(5.2-44.8)$ & Reference & & 37 & $46.1 \%(38.1-54.1)$ & Reference & \\
\hline & $\begin{array}{l}\text { Night (11:00 } \\
\text { p.m.) }\end{array}$ & 12 & $71.4 \%(42.3-100)$ & $2.28(1.14-3.51)$ & 0.071 & 36 & $72.4 \%(55.2-89.6)$ & $2.46(1.36-4.58)$ & 0.046 \\
\hline & $\begin{array}{l}\text { Morning (6:00 } \\
\text { a.m.) }\end{array}$ & 16 & $83.3 \%(67.0-99.6)$ & $3.12(1.26-5.42)$ & $<0.001$ & 36 & $74.6 \%(62.1-87.1)$ & $4.42(2.02-6.21)$ & $<0.001$ \\
\hline \multirow{3}{*}{$\begin{array}{l}\text { Studies in village } \\
\text { houses in rural Tanza- } \\
\text { nia occupied by local } \\
\text { villagers }\end{array}$} & $\begin{array}{l}\text { Evening (6:00 } \\
\text { p.m.) }\end{array}$ & 130 & $75.5 \%(67.8-83.2)$ & Reference & & 115 & $80.9 \%(72.8-89.0)$ & Reference & \\
\hline & $\begin{array}{l}\text { Night (11:00 } \\
\text { p.m.) }\end{array}$ & 107 & $85.9 \%(78.8-93.0)$ & $2.09(1.06-4.14)$ & 0.03 & 128 & $87.6 \%(81.7-93.5)$ & $1.63(0.83-3.19)$ & 0.15 \\
\hline & $\begin{array}{l}\text { Morning (6:00 } \\
\text { a.m.) }\end{array}$ & 113 & $94.7 \%(90.7-98.7)$ & $6.14(2.56-14.74)$ & $<0.001$ & 126 & $91.2 \%(86.5-95.9)$ & $2.79(1.30-6.02)$ & 0.01 \\
\hline
\end{tabular}

$O R$ Odds ratio

a Confidence interval of the mean

The mean proportions of inseminated An. funestus females were $16.8 \%(95 \% \mathrm{CI}: \pm 8.3 \%)$ in the exit traps, 25.2\% (95\% CI: $\pm 3.4 \%$ ) inside the huts and 20.9\% (95\% $\mathrm{CI}: \pm 2.8 \%)$ outside the huts; in comparison, the mean proportions of inseminated An. arabiensis females were $37.1 \%(95 \% \mathrm{CI}: \pm 6.8 \%)$ in the window exit traps, 47.4\% (95\% CI: $\pm 4.7 \%$ ) inside the huts and $42.3 \%$ (95\% CI: $\pm 5.5 \%$ ) outside the huts (Table 2). Further analysis of the An. funestus data showed that the insemination rates were significantly higher indoors and lower in the exit traps compared to the outdoors $(P \leq 0.03)$. There was also a difference in insemination rates in $A n$. arabiensis caught indoors versus outdoors although this difference was not statistically significant $(P=0.11)$. The same trend was observed for this species in samples collected from exit traps and outdoors, with the difference being marginal $(P=0.13)$ (Table 2). The proportions of inseminated $A n$. arabiensis were consistently higher than those of inseminated An. funestus across all collection locations (outdoors, indoors and in the window exit traps) $(P<0.001)$ (Table 2).

PCR analysis of the 905 emerged adult An. funestus in the semi-field study revealed that $84.9 \%(n=769)$ were An. funestus s.s., $6.5 \%(n=59)$ were Anopheles rivulorum, $0.9 \%(n=8)$ were Anopheles leesoni and the remaining $7.6 \%(n=69)$ were unamplified. While most of the mosquitoes mating indoors and outdoors were An. funestuss.s. or An. arabiensis, there were also $A n$. rivulorum mosquitoes that mated both indoors and outdoors.

\section{Discussion}

Mating in mosquitoes is considered to occur as in many other dipterans, mostly in swarms in different arenas [30], but it is recognized that mating can also occur independently of swarms [39]. The focus of this study was to investigate the indoor and outdoor mating successes of the main malaria vectors in rural Tanzania, An. funestus and $A n$. arabiensis. The study used a four-phase approach consisting of: (i) assessment of indoor resting densities of male mosquitoes inside human dwellings in rural villages; (ii) field observations of wild mosquitoes entering huts occupied by volunteers that had been constructed in the same villages; (iii) field observation of insemination status of wild mosquitoes trapped from natural houses in the village; and (iv) semi-field observations of wildcaught mosquitoes to verify and quantify insemination indoors and outdoors.

The three main findings were as follows: (i) a significant number of male mosquitoes rest indoors in different house types and the densities of these male mosquitoes are highest during the morning; (ii) approximately $60 \%$ of female Anopheles mosquitoes collected indoors were already inseminated at 6 p.m., but this proportion increased to $90 \%$ by the following morning even when the huts remained closed after the 6.p.m collection, 
implying additional mating indoors despite no additional mosquito entry; and (iii) under semi-field settings, wildcaught Anopheles mosquitoes held inside huts mated as frequently as those outdoors.

These observations confirm that while most mating in the wild may be happening outdoors, there is substantial additional mating that can occur after the mosquitoes are already indoors. Both An. funestus and An. arabiensis show this flexibility in behaviour although indoor insemination appeared to be more prominent in An. funestus for which indoor insemination exceeded that outdoors. The experimental hut studies conducted by Dao et al. [39] in West Africa found that mating in mosquitoes exiting huts was $5 \%$ higher than that in those entering, thus providing the first indications of this phenomenon in malaria mosquitoes. Our study supports that original hypothesis but also demonstrates that indoor mating can be far more substantial. Moreover, unlike the outdoor mating in swarms, which typically happens at dusk [33, 36, $56,57]$, the present study shows that indoor mating can happen far later in the evening and also during the night. Our field study showed a gradual increase in insemination from approximately $60 \%$ at 6 p.m. to $80 \%$ at 11 p.m. and finally to $90 \%$ at 6 a.m. the following morning, suggesting continued mating events throughout the night. Since no observations were made of any swarms indoors, it is unclear whether the indoor mating is a function of swarms or otherwise.

This study also highlights the influence of different house types on indoor resting densities of male mosquitoes. Males of both An. funestus and An. arabiensis showed a preference for less improved houses, such as those with thatched roofs, compared to more improved houses, such as those with metal roofs. Similar preferences have been demonstrated in Anopheles females in several studies $[49,58,59]$. One clear implication of this observation is that indoor interventions that typically target host-seeking female mosquitoes, such as indoor residual spraying (IRS) [15], may also impact males, possibly explaining why IRS campaigns have been particularly effective against An. funestus populations, for which substantial densities of males rest indoors $[60,61]$. Fortunately, insecticide resistance surveys in rural Tanzania have shown that Anopheles males have a similar phenotypic expression of resistance as their conspecific females, and would therefore respond similarly to nonpyrethroid IRS treatments [62]. Similarly, some of the new vector control tools being evaluated to complement ITNs and IRS, notably attractive toxic sugar baits $[26,28$, 63 ], could be optimized to target male and female mosquitoes indoors.

An important question is whether the experimental set-up used in this study induced the observed indoor insemination or whether this was entirely a natural phenomenon. While it is impossible to rule out an impact of the experimental set-up, the actual findings suggest that indoor mating is a natural phenomenon, albeit occurring at a lower frequency than outdoor mating. The natural observation of males indoors suggests that there are several opportunities for the female and male mosquitoes to copulate. Moreover, the experimental huts used in the semi-field observations were unnatural and fitted with window exit traps so that flying mosquitoes could exit but not enter the huts. Yet there was still substantial insemination indoors, with the mean proportions being equal to or higher than those observed outdoors or in exit traps. It can be inferred, therefore, that both An. funestus and An. arabiensis adults could voluntarily mate indoors despite the unrestricted egress routes. This inference was confirmed by the observed indoor insemination in local village houses, which remained unsealed during the experiment. Future studies should examine the proportions of virgin females at different time points during the night, and the potential effect of egressing virgins on the proportion of residual female indoors that are inseminated.

All of the field studies were completed on a nightly basis and the huts cleaned thoroughly each day. The field observations cannot therefore be used to infer the true quantities of indoor mating in nature but are merely an indication that this phenomenon does indeed happen. Interestingly, however, most of the mosquitoes that entered the huts had already mated. As can be seen in the field data, approximately two thirds of the Anopheles females were already inseminated when they entered the huts. Most likely these females had already left the swarm stations. We found a small but consistent additional mating of about $30 \%$ in the first round in the experimental huts and approximately $19 \%$ in the local dwellings. It would appear that when confined, and in the absence of any additional recruitment of males or females, the actual proportions of inseminated mosquitoes will be high even if any additional insemination indoors is minimal. Another question is whether swarming was actually necessary for such indoor mating. We did not observe any evidence of swarming indoors; thus, the indoor mating observed in our study appeared to be happening without any apparent swarming. However, our findings must be considered to be preliminary, and it is important that this specific question be evaluated in future research.

Another limitation of this study was that neither the gonotrophic state of the females nor the status of the genitalia of the males were observed. Direct observations of the rotation of the male genitalia to assess sexual maturity or their antennas to assess readiness for mating could improve the degree of certainty for the indoor mating 


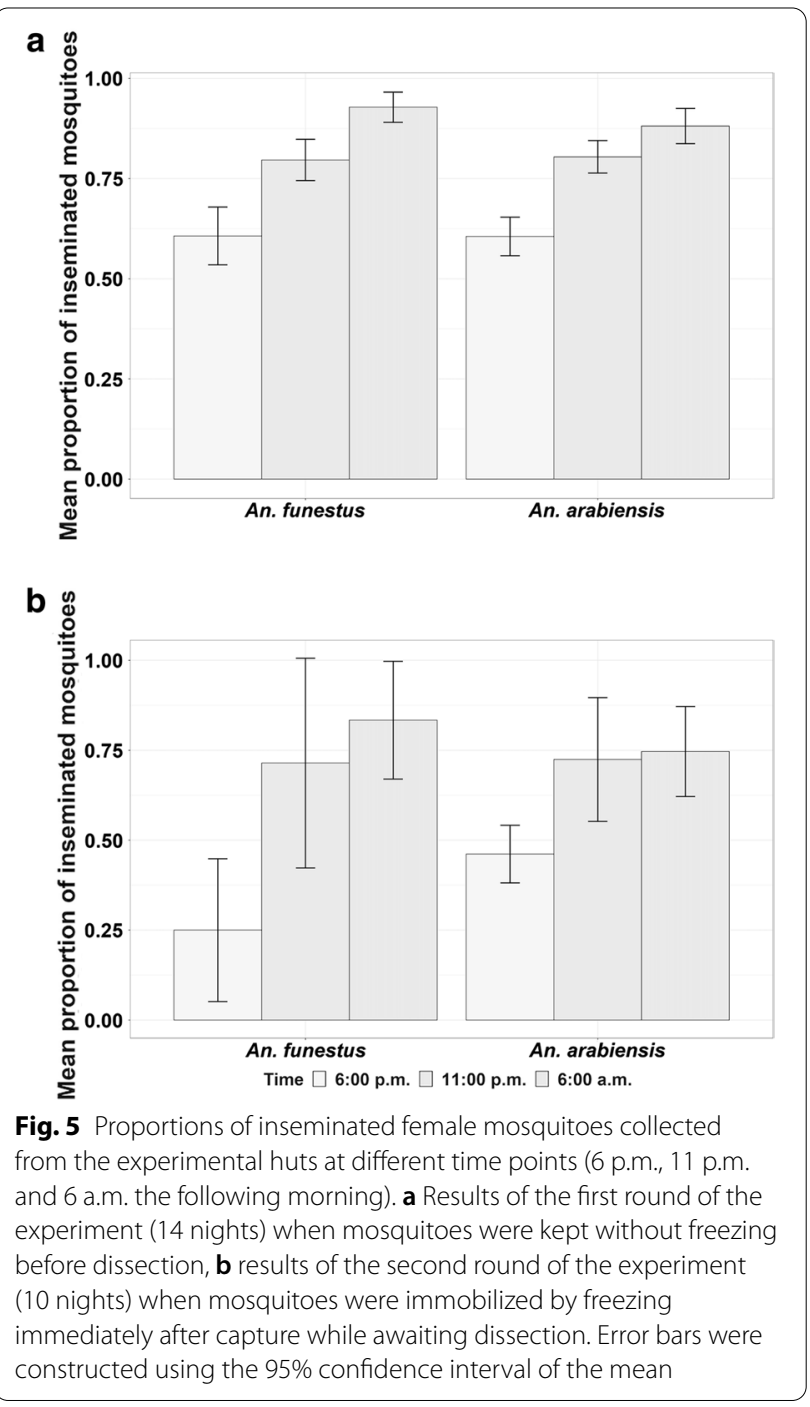

phenomena. It will be interesting to assess changes in gonotrophic state of the female, how this changes overnight and whether there are any correlations between this and the insemination rates. It is also possible that the trapping methods used, in particular the human landing catches, may have introduced some biases, although these do not invalidate the overall findings.

To accelerate efforts towards malaria elimination, the deployment of novel approaches to complement current vector control (ITNs and IRS) are essential [16]. Such tools should particularly mitigate current challenges, such as insecticide resistance to the commonly used pyrethroids [64-67] and outdoor biting by malaria vectors [68-73]. The findings of this study on mating behavior, among other aspects of the Anopheles life-cycle processes, may provide insights towards the development or improvement of malaria vector control. The results may be used to design or improve indoor insecticidal methods targeting males, females or both, as well as niche products such as ATSBs to also target male and female mosquitoes indoors and outdoors.

Another potential opportunity from these findings is in the area of mosquito colonization inside laboratories, which is currently a challenge for some vector species. In particular, $A n$. funestus, which mediates significant proportions of ongoing malaria transmission, particularly in southern and East Africa, remains one of the most difficult mosquito species to rear inside laboratories. Laboratory colonies are an essential requirement for experimental studies under controlled conditions, such as enabling characterization of insecticide resistance $[62,74,75]$ as well as studies on other genetic traits $[76,77]$, immune strategies $[78,79]$ and key vector demographic profiles [80-82]. Unlike An. gambiae, An. funestus remains extremely difficult to colonize and maintain inside laboratories, partly because it is eurygamic (does not mate in captivity) and has poorly understood ecological needs. To our knowledge, only two strains have been successfully colonized from wild populations despite several attempts, both at the Vector Control Reference Laboratory (VCRL) in the National Institute for Communicable Diseases, South Africa, from populations collected in Angola (FANG) and Mozambique (FUMOZ) [44]. The FUMOZ strain is also maintained at other laboratories worldwide, including in Cameroon, UK [75] and Tanzania [45].

The field observations by Dao et al. focused on $A n$. coluzzii and demonstrated that under confinement there was a breakdown of the cross-species mating barrier when other species were added indoors in experimental houses [39]. This suggests that indoor conditions are not sufficiently representative of actual mating conditions in the wild, but that the same conditions could be favorable for breaking the bottlenecks associated with mating in some species, such as An. funestus, which have been challenging to rear inside laboratories, partly because of poor mating. The present study improves upon the experiments by Dao et al. [39] by introducing controlled observations in both the semi-field and field settings and validating the observations underconditions of both restricted and unrestricted egress.

Several attempts are being made to colonize new $A n$. funestus strains [83] from wild populations, but methods used to establish FUMOZ and FANG have not been successful elsewhere [84], including those attempted in the same wild populations from which FUMOZ was originally derived (M Coetzee, personal communication). The inability to repeatedly colonize and establish An. funestus in laboratories is responsible for the more limited understanding of the biology of this species compared to other vector species. Recent evidence from colonization 
Table 2 Mean proportion of inseminated Anopheles funestus and Anopheles arabiensis from the semi-field experiment

\begin{tabular}{|c|c|c|c|c|c|c|c|c|c|}
\hline & \multirow{2}{*}{$\begin{array}{l}\text { Collection } \\
\text { setting }\end{array}$} & \multicolumn{4}{|c|}{ Anopheles funestus } & \multicolumn{4}{|c|}{ Anopheles arabiensis } \\
\hline & & $\begin{array}{l}\text { No. females } \\
\text { collected }\end{array}$ & $\begin{array}{l}\text { Proportion } \\
\text { inseminated (95\% } \\
\text { Cl) }\end{array}$ & $\begin{array}{l}\text { OR }(95 \% \mathrm{Cl}) \text { for } \\
\text { insemination }\end{array}$ & $P$-value & $\begin{array}{l}\text { No. females } \\
\text { collected }\end{array}$ & $\begin{array}{l}\text { Proportion } \\
\text { inseminated (95\% } \\
\text { Cl) }\end{array}$ & $\begin{array}{l}\text { OR }(95 \% \mathrm{Cl}) \text { for } \\
\text { insemination }\end{array}$ & r P-value \\
\hline \multirow{5}{*}{$\begin{array}{l}\text { Studies in semi- } \\
\text { field system }\end{array}$} & i-Outdoor & 908 & $20.9 \%(18.1-23.7$ & Ref & & 568 & $42.3 \%(36.8-47.8)$ & \multicolumn{2}{|l|}{ Ref } \\
\hline & Indoor & 792 & $25.2 \%(21.8-28.6)$ & $0.56(0.51-0.62)$ & 0.03 & 568 & $47.4 \%(42.7-52.1)$ & \multicolumn{2}{|c|}{$0.55(0.49-0.61) 0.11$} \\
\hline & Exit trap & 133 & $16.8 \%(8.5-25.1)$ & $0.36(0.26-0.48)$ & 0.026 & 298 & $37.1 \%(30.3-43.9)$ & \multicolumn{2}{|c|}{$0.44(0.37-0.52) 0.13$} \\
\hline & & \multirow[t]{2}{*}{ Anopheles sp. } & \multicolumn{2}{|l|}{ Indoor } & \multicolumn{3}{|c|}{ Outdoor } & \multicolumn{2}{|l|}{ Exit trap } \\
\hline & & & OR $(95 \% \mathrm{Cl})$ & $P$-value & OR $(95 \%$ & $\%(\mathrm{Cl})$ & P-value & OR $(95 \% \mathrm{Cl}) \quad P$ & $P$-value \\
\hline \multirow{2}{*}{\multicolumn{2}{|c|}{$\begin{array}{l}\text { Interspecies comparison in a } \\
\text { semi-field experiment }\end{array}$}} & An. funestus & Ref & & Ref & & & Ref & \\
\hline & & An. arabiensis & $1.79(1.33-2.41)$ & $<0.001$ & \multicolumn{2}{|c|}{$2.23(1.62-3.08)$} & $<0.001$ & $\begin{array}{l}2.94 \\
(1.77-4.90)\end{array}$ & $<0.001$ \\
\hline
\end{tabular}

OR Odds ratio

attempts in Tanzania has highlighted mating as one of the bottlenecks to colonization [45]. The findings in the present study may therefore enable advancement towards alternative colonization processes either inside laboratories or by using semi-field chambers and experimental huts in which natural mating can happen.

\section{Conclusion}

This study demonstrates that wild populations of $A n$. funestus and An. arabiensis can mate both inside and outside dwellings. Most mating likely happens outdoors

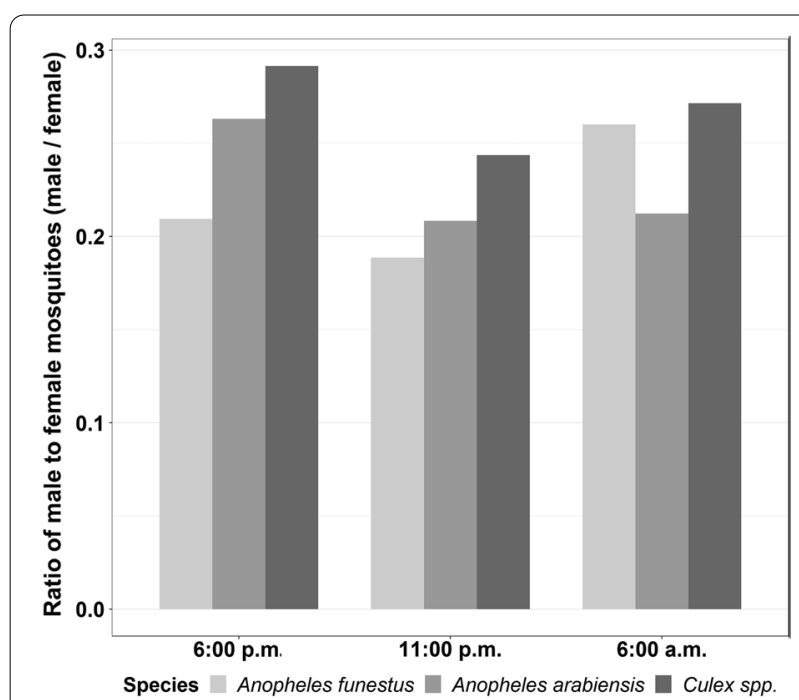

Fig. 6 The ratio of male to female mosquitoes collected in the experimental huts calculated as the sum of males per total females collected in each house at different time points before the mosquitoes enter houses, but significant additional mating can happen indoors. The indoor insemination in huts with exit traps indicates that mosquitoes can voluntarily mate indoors despite unrestricted egress. These findings may be relevant for improving vector control by targeting male mosquitoes and may also inform improved efforts to colonize Anopheles species inside laboratories or semi-field chambers.

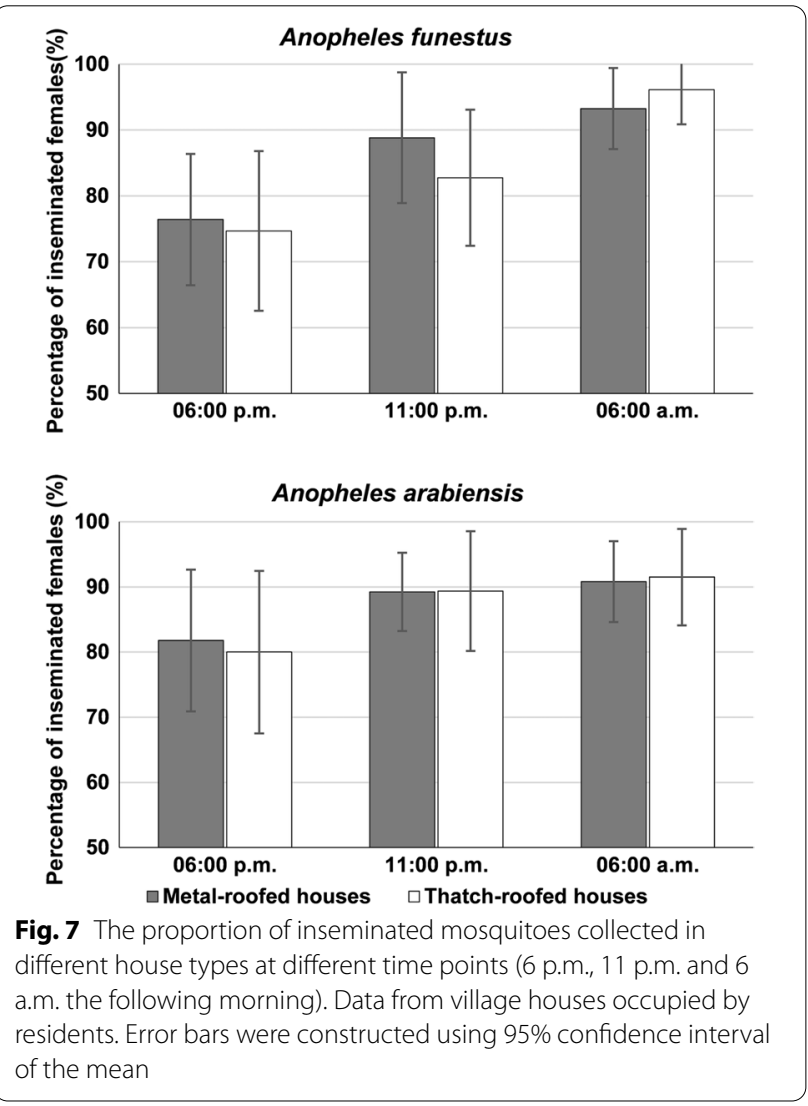




\section{Abbreviations}

Cl: Confidence interval; GMM: Genetically modified mosquitoes; ITNs: Insecticide-treated nets; IRS: Indoor residual spraying; SIT: Sterile insect techniques; PCR: Polymerase chain reaction.

\section{Supplementary Information}

The online version contains supplementary material available at https://doi. org/10.1186/s13071-021-04989-8.

Additional file 1. Male mosquitoes in different house categories and collection time.

\section{Acknowledgements}

Many thanks to the volunteers who participated in the collection of mosquitoes for both field and semi-field experiments. We also gratefully thank Gerald Tamayamali, Nicolaus Mhumbira, Richard Lumuli and Karimu Mchwembo for assisting in larval collection for the semi-field experiment. Also, the authors would like to extend their gratitude to all staff members at the Ifakara Health Institute for providing great support and many opinions regarding the experiment.

\section{Authors' contributions}

IHN, BJM, MH, EWK, HSN and FOO conceived the study and developed the study protocol. IHN and BJM produced the first drafts of the manuscript. IHN, BJM, HSN, LLM and FOO analyzed the data. IHN, BJM, IHM, NFK and EWK conducted the experiments. IHN, GM and DMM dissected the mosquitoes. IHN, BJM and NFK created the study site map. IHN, BJM, HSN, LLM, IHM, NFK, $\mathrm{RMN}, \mathrm{EEH}, \mathrm{MH}, \mathrm{FT}, \mathrm{HMF}, \mathrm{EWK}$ and $\mathrm{FOO}$ reviewed the manuscript and provided inputs. All authors have read and contributed to the final manuscript.

\section{Funding}

The activities in this work were supported by Howard Hughes Medical Institute (HHMI) — Gates International Research Scholar Award to FO at Ifakara Health Institute (OPP1175877) and Bill \& Melinda Gates Foundation Grant, also to Ifakara Health Institute (INV-002138). IHN was funded by the University of Glasgow GCRF Small Grants Fund, which is supported by a Global Challenges Research Fund allocation from the Scottish Funding Council. Also, EWK was funded by NIHR-Wellcome Trust Partnership for Global Health Research International Training Fellowship (Grant Number: 216448/Z/19/Z). HMF was supported by funding from the Medical Research Council UK (MR/T008873/1).

\section{Availability of data and materials}

All data generated from this study will be available from the corresponding authors upon request.

\section{Declarations}

\section{Ethics approval and consent to participate}

Ethical approval for this study was obtained from Ifakara Health Institute Institutional Review Board (IHI/IRB/No: 26-2020), and the National Institute of Medical Research (NIMR) through the Medical Research Coordinating Committee (MRCC) (Ref: NIMR/HQ/R.8a/Nol. IX/3495). Before the commencement of the study, meetings were held with volunteers who participated in mosquito collection to explain the purpose and procedures of the study, following which all volunteers who agreed to participate in the study signed consent forms.

\section{Consent for publication}

This manuscript has been approved for publication by the National Institute of Medical Research, Tanzania (NIMR/HQ/P.12 VOL XXXII/64).

\section{Competing interest}

The authors declare that they have no competing interests.

\section{Author details}

${ }^{1}$ Environmental Health and Ecological Sciences Department, Ifakara Health Institute, P.O. Box 53, Ifakara, Tanzania. ${ }^{2}$ Institute of Biodiversity, Animal Health and Comparative Medicine, University of Glasgow, Glasgow, UK. ${ }^{3}$ School of Life Science and Bioengineering, The Nelson Mandela African Institution of Sciences \& Technology, Arusha, Tanzania. ${ }^{4}$ School of Public Health, Faculty of Health Sciences, University of the Witwatersrand, Park Town, Republic of South Africa. ${ }^{5}$ Disease Vector Group, Chemical Ecology, Department of Plant Protection Biology, Swedish University of Agricultural Sciences, Alnarp, Sweden. ${ }^{6}$ Centre for Applied Entomology and Parasitology, School of Life Sciences, Keele University, Newcastle-under-Lyme, UK.

Received: 28 April 2021 Accepted: 1 September 2021

Published online: 07 October 2021

\section{References}

1. White GB. Anopheles gambiae complex and disease transmission in Africa. Trans R Soc Trop Med Hyg. 1974;68(4):278-98.

2. Sinka ME, Bangs MJ, Manguin S, Rubio-Palis Y, Chareonviriyaphap T, Coetzee $M$, et al. A global map of dominant malaria vectors. Parasit Vectors. 2012;5:69.

3. Sinka ME, Bangs MJ, Manguin S, Coetzee M, Mbogo CM, Hemingway J, et al. The dominant Anopheles vectors of human malaria in Africa, Europe and the Middle East: occurrence data, distribution maps and bionomic précis. Parasit Vectors. 2010;3:117.

4. Coetzee M, Koekemoer LL. Molecular systematics and insecticide resistance in the major African malaria vector Anopheles funestus. Annu Rev Entomol. 2013;58:393-412.

5. World Health Organization. World malaria report 2020: 20 years of global progress and challenges. 2020. Geneva: World Health Organization. https://www.who.int/publications/i/item/9789240015791. Accessed 14 Sept 2021.

6. World Health Organization. World malaria report 2019. 2019. Geneva: World Health Organization. https://www.who.int/publications/i/item/ 9789241565721. Accessed 14 Sept 2021.

7. World Health Organization. Global technical strategy for malaria 2016-2030. Global Malaria Programme. 2025. Geneva: World Health Organization. https://www.who.int/publications/i/item/9789240031357. Accessed 14 Sept 2021

8. Bhatt S, Weiss DJ, Cameron E, Bisanzio D, Mappin B, Dalrymple U, et al. The effect of malaria control on Plasmodium falciparum in Africa between 2000 and 2015. Nature. 2015;526:207-11.

9. Eisele TP, Larsen DA, Walker N, Cibulskis RE, Yukich JO, Zikusooka CM, et al. Estimates of child deaths prevented from malaria prevention scale-up in Africa 2001-2010. Malar J. 2012;11:93.

10. Eisele TP, Bennett A, Silumbe K, Finn TP, Porter TR, Chalwe V, et al. Impact of four rounds of mass drug administration with dihydroartemisininpiperaquine implemented in Southern Province. Zambia Am J Trop Med Hyg. 2020;103:7-18.

11. Galatas B, Saúte F, Martí-Soler H, Guinovart C, Nhamussua L, Simone W, et al. A multiphase program for malaria elimination in southern Mozambique (the Magude project): a before-after study. PLoS Med. 2020;17:e1003227.

12. Pluess B, Tanser FC, Lengeler C, Sharp BL. Indoor residual spraying for preventing malaria. Cochrane Database Syst Rev. 2010;(4):CD006657. https:// doi.org/10.1002/14651858.CD006657.pub2.

13. Okumu F. The fabric of life: what if mosquito nets were durable and widely available but insecticide-free? Malar J. 2020;19(1):260.

14. Okumu F, Moore S. Combining indoor residual spraying and insecticidetreated nets for malaria control in Africa: a review of possible outcomes and an outline of suggestions for the future. Malar J. 2011;10:208.

15. World Health Organization. Indoor residual spraying. Use of indoor residual spraying for scaling up global malaria control and elimination (archived). 2006. Geneva:World Health Organization. https://apps.who. int/iris/handle/10665/69386. Accessed 14 Sept 2021.

16. malERA Consultative Group on Vector Control. A research agenda for malaria eradication: vector control. PLoS Med. 2011:8:e1000401.

17. malERA Refresh Consultative Panel on Tools for Malaria Elimination T. malERA: an updated research agenda for diagnostics, drugs, vaccines, 
and vector control in malaria elimination and eradication. PLoS Med 2017; 14(11):e1002455.

18. Ferguson HM, Dornhaus A, Beeche A, Borgemeister C, Gottlieb M, Mulla $M S$, et al. Ecology: a prerequisite for malaria elimination and eradication. PLoS Med. 2010;7:8.

19. Sawadogo SP, Niang A, Bilgo E, Millogo A, Maïga H, Dabire RK, et al. Targeting male mosquito swarms to control malaria vector density. PLoS ONE. 2017;12:e0173273.

20. Alphey L, Benedict M, Bellini R, Clark GG, Dame DA, Service MW, et al. Sterile-insect methods for control of mosquito-borne diseases: an analysis. Vector Borne Zoonotic Dis. 2010;10:295-311.

21. Christophides GK. Transgenic mosquitoes and malaria transmission. Cell Microbiol. 2005;7(3):325-33.

22. Diabate A, Tripet F. Targeting male mosquito mating behaviour for malaria control. Parasit Vectors. 2015;8:1.

23. Carvalho DO, McKemey AR, Garziera L, Lacroix R, Donnelly CA, Alphey $L$, et al. Suppression of a field population of Aedes aegypti in Brazil by sustained release of transgenic male mosquitoes. PLOS Negl Trop Dis. 2015;9:e0003864.

24. Vreysen MJB, Saleh KM, Ali MY, Abdulla AM, Zhu Z-R, Juma KG, et al. Glossina austeni (Diptera: Glossinidae) eradicated on the island of Unguja, Zanzibar, using the sterile insect technique. J Econ Entomol. 2000;93:123-35.

25. Koyama J, Kakinohana H, Miyatake T. Eradication of the melon fly, Bactrocera cucurbitae, in Japan: importance of behavior, ecology, genetics, and evolution. Annu Rev Entomol. 2004;49:331-49.

26. Traore MM, Junnila A, Traore SF, Doumbia S, Revay EE, Kravchenko VD, et al. Large-scale field trial of attractive toxic sugar baits (ATSB) for the control of malaria vector mosquitoes in Mali, West Africa. Malar J. 2020;19:72.

27. Müller GC, Beier JC, Traore SF, Toure B, Traore MM, Bah S. Successful field trial of attractive toxic sugar bait (ATSB) plant-spraying methods against malaria vectors in the Anopheles gambiae complex in Mali, West Africa. Malar J. 2010;9:210.

28. Qualls WA, Müller GC, Traore SF, Traore MM, Arheart KL, Doumbia S, et al. Indoor use of attractive toxic sugar bait (ATSB) to effectively control malaria vectors in Mali, west Africa. Malar J. 2015;14:301.

29. Clement A. Biology of mosquitoes: sensory reception and behaviour. Wallingford: CABI Publishing; 1999.

30. Downes JA. The swarming and mating flight of Diptera. Annu Rev Entomol. 1969;14:271-98.

31. Rund SSC, Lee SJ, Bush BR, Duffield GE. Strain- and sex-specific differences in daily flight activity and the circadian clock of Anopheles gambiae mosquitoes. J Insect Physiol. 2012:58:1609-19.

32. Jones MDR, Gubbins SJ, Cubbin CM. Circadian flight activity in four sibling species of the Anopheles gambiae complex (Diptera, Culicidae). Bull Entomol Res. 1974;64:241-6.

33. Kaindoa EW, Ngowo HS, Limwagu A, Mkandawile G, Kihonda J, Masalu JP, et al. New evidence of mating swarms of the malaria vector, Anopheles arabiensis in Tanzania. Wellcome Open Res. 2017;2:88.

34. Niang A, Nignan C, Serge Poda B, Sawadogo SP, Roch Dabiré K, Gnankiné $\mathrm{O}$, et al. Semi-field and indoor setups to study malaria mosquito swarming behavior. Parasit Vectors. 2019;12:446.

35. Mozūraitis R, Hajkazemian M, Zawada JW, Szymczak J, Pålsson K, Sekar V, et al. Male swarming aggregation pheromones increase female attraction and mating success among multiple African malaria vector mosquito species. Nat Ecol Evol. 2020;4(10):1395-401.

36. Kaindoa EW, Ngowo HS, Limwagu AJ, Tchouakui M, Hape E, Abbasi S, et al. Swarms of the malaria vector Anopheles funestus in Tanzania. Malar J. 2019;18:29.

37. Zawada JW, Moss YLD, Muleba M, Dabire RK, Maïga H, Venter N, et al. Molecular and physiological analysis of Anopheles funestus swarms in Zambia. Malar J. 2018;17:49.

38. Achinko D, Thailayil J, Paton D, Mireji PO, Talesa V, Masiga D, et al. Swarming and mating activity of Anopheles gambiae mosquitoes in semi-field enclosures. Med Vet Entomol. 2016:30:14-20.

39. Dao A, Adamou A, Yaro AS, Mai HM, Lehmann T, Kassogue Y. Assessment of alternative mating strategies in Anopheles gambiae: Does mating occur indoors? J Med Entomol. 2008:45:643-52.

40. Kaindoa EW, Matowo NS, Ngowo HS, Mkandawile G, Mmbando A, Finda $\mathrm{M}$, et al. Interventions that effectively target Anopheles funestus mosquitoes could significantly improve control of persistent malaria transmission in south-eastern Tanzania. PLoS ONE. 2017;12:e177807.

41. Swai JK, Mmbando AS, Ngowo HS, Odufuwa OG, Finda MF, Mponzi $W$, et al. Protecting migratory farmers in rural Tanzania using eave ribbons treated with the spatial mosquito repellent, transfluthrin. Malar J. 2019;18:414.

42. Mccann RS, Ochomo E, Bayoh MN, Vulule JM, Hamel MJ, Gimnig JE, et al. Reemergence of Anopheles funestus as a vector of Plasmodium falciparum in western Kenya after long-term implementation of insecticide-treated bed nets. Am J Trop Med Hyg. 2014;90:597-604.

43. Gimnig JE, Ombok M, Kamau L, Hawley WA. Characteristics of larval anopheline (Diptera: Culicidae) habitats in western Kenya. J Med Entomol. 2001;38:282-8.

44. Hunt RH, Brooke BD, Pillay C, Koekemoer LL, Coetzee M. Laboratory selection for and characteristics of pyrethroid resistance in the malaria vector Anopheles funestus. Med Vet Entomol. 2005;19:271-5.

45. Ngowo HS, Hape EE, Matthiopoulos J, Okumu FO, Ferguson HM, Okumu FO. Fitness characteristics of the malaria vector, Anopheles funestus, during an attempted laboratory colonization. Malar J. 2021;20:148.

46. Finda MF, Limwagu AJ, Ngowo HS, Matowo NS, Swai JK, Kaindoa E, et al. Dramatic decreases of malaria transmission intensities in Ifakara, southeastern Tanzania since early 2000s. Malar J. 2018;17:362

47. Lwetoijera DW, Harris C, Kiware SS, Dongus S, Devine GJ, Mccall PJ, et al. Increasing role of Anopheles funestus and Anopheles arabiensis in malaria transmission in the Kilombero valley, Tanzania. Malar J. 2014;13:331.

48. Ferguson HM, Ng'habi KR, Walder T, Kadungula D, Moore SJ, Lyimo I, et al. Establishment of a large semi-field system for experimental study of African malaria vector ecology and control in Tanzania. Malar J. 2008;7:158.

49. Msugupakulya BJ, Kaindoa EW, Ngowo HS, Kihonda JM, Kahamba NF, Msaky DS, et al. Preferred resting surfaces of dominant malaria vectors inside different house types in rural south_eastern Tanzania. Malar J. 2020;19:22.

50. Gillies MT, Coetzee M. A supplement to the Anophelinae of Africa South of the Sahara (Afrotropical Region). Johannesburg: South African Institute for Medical Research; 1987.

51. Coetzee M. Key to the females of Afrotropical Anopheles mosquitoes (Diptera: Culicidae). Malar J. 2020;19:70.

52. World Health Organization. Manual on practical entomology in malaria Part II. 1975. Geneva: World Health Organization. https://www.worldcat. org/title/manual-on-practical-entomology-in-malaria-part-2-methodsand-techniques/oclc/58852809. Accessed 14 Sept 2021.

53. Nambunga IH, Ngowo HS, Mapua SA, Hape EE, Msugupakulya BJ, Msaky $D S$, et al. Aquatic habitats of the malaria vector Anopheles funestus in rural south-eastern Tanzania. Malar J. 2020;19:219.

54. Koekemoer LL, Kamau L, Hunt RH, Coetzee M. A cocktail polymerase chain reaction assay to identify members of the Anopheles funestus (Diptera: (ulicidae) group. Am J Trop Med Hyg. 2002;66:804-11.

55. R Development Core Team. A language and environment for statistical computing. Vienna: R Foundation for Statistical Computing; 2016.

56. Sawadogo PS, Namountougou M, Toé KH, Rouamba J, Maïga H, Ouédraogo KR, et al. Swarming behaviour in natural populations of Anopheles gambiae and An. coluzzii. Review of 4 years survey in rural areas of sympatry, Burkina Faso (West Africa). Acta Trop. 2014;132:542-52.

57. Diabaté A. Characterization of the mating systems of Anopheles gambiae in malaria control perspective. Malar J. 2012;11:2012.

58. Atieli H, Menya D, Githeko A, Scott T. House design modifications reduce indoor resting malaria vector densities in rice irrigation scheme area in western Kenya. Malar J. 2009;8:108.

59. Thomas S, Ravishankaran S, Justin NAJA, Asokan A, Mathai MT, Valecha N, et al. Resting and feeding preferences of Anopheles stephensi in an urban setting, perennial for malaria. Malar J. 2017;16:111.

60. Gillies M, Smith A. The effect of a residual house-spraying campaign in East Africa on species balance in the Anopheles funestus group. The replacement of An. funestus Giles by An. rivulorum leeson. Bull Entomol Res. 1960;51:243-52.

61. Mabaso MLH, Sharp B, Lengeler C. Historical review of malarial control in southern African with emphasis on the use of indoor residual housespraying. Trop Med Int Health. 2004;9:846-56.

62. Matowo NS, Munhenga G, Tanner M, Coetzee M, Feringa WF, Ngowo $\mathrm{HS}$, et al. Fine-scale spatial and temporal heterogeneities in insecticide 
resistance profiles of the malaria vector, Anopheles arabiensis in rural south-eastern Tanzania. Wellcome Open Res. 2017;2:96.

63. Stewart ZP, Oxborough RM, Tungu PK, Kirby MJ, Mark W, Irish SR. Indoor application of attractive toxic sugar bait (ATSB) in combination with mosquito nets for control of pyrethroid-resistant mosquitoes. PLoS ONE. 2013;8:e84168.

64. Riveron JM, Osae M, Egyir-yawson A, Irving H, Ibrahim SS, Wondji CS. Multiple insecticide resistance in the major malaria vector Anopheles funestus in southern Ghana: implications for malaria control. Parasit Vectors. 2016;9:504

65. Nkya TE, Akhouayri I, Kisinza W, David JP. Impact of environment on mosquito response to pyrethroid insecticides: facts, evidences and prospects. Insect Biochem Mol Biol. 2013;43:407-16.

66. Djouaka R, Riveron JM, Yessoufou A, Tchigossou G, Akoton R, Irving H, et al. Multiple insecticide resistance in an infected population of the malaria vector Anopheles funestus in Benin. Parasit Vectors. 2016;9:453.

67. Menze BD, Riveron JM, Ibrahim SS, Irving H, Antonio-nkondjio C, Awonoambene $\mathrm{PH}$, et al. Multiple insecticide resistance in the malaria vector Anopheles funestus from northern Cameroon is mediated by metabolic resistance alongside potential target site insensitivity mutations. PLoS ONE. 2016;11:e0163261.

68. Moiroux N, Gomez MB, Pennetier C, Elanga E, Djènontin A, Chandre F, et al. Changes in Anopheles funestus biting behavior following universal coverage of long-lasting insecticidal nets in Benin. J Infect Dis. 2012;206:1622-9.

69. Russell TL, Govella NJ, Azizi S, Drakeley CJ, Kachur SP, Killeen GF. Increased proportions of outdoor feeding among residual malaria vector populations following increased use of insecticide-treated nets in rural Tanzania. Malar J. 2011;10:80.

70. Govella NJ, Ferguson H. Why use of interventions targeting outdoor biting mosquitoes will be necessary to achieve malaria elimination. Front Physiol. 2012;3:199.

71. Reddy MR, Overgaard HJ, Abaga S, Reddy VP, Caccone A, Kiszewski AE, et al. Outdoor host seeking behaviour of Anopheles gambiae mosquitoes following initiation of malaria vector control on Bioko Island, Equatorial Guinea. Malar J. 2011;10:184

72. Sembène $P$, Doucouré $S$, Ndiath M, Sougoufara S, Diagne N, Trape J-F, et al. Biting by Anopheles funestus in broad daylight after use of longlasting insecticidal nets: a new challenge to malaria elimination. Malar J. 2014;13:125.

73. Sougoufara S, Doucouré S, Sembéne PMB, Harry M, Sokhna C. Challenges for malaria vector control in sub-Saharan Africa: Resistance and behavioral adaptations in Anopheles populations. J Vector Borne Dis. 2017:54(1):4-15

74. Ranson H, Abdallah H, Badolo A, Guelbeogo W, Kerah-Hinzoumbé C, Yangalbé-Kalnoné E, et al. Insecticide resistance in Anopheles gambiae: data from the first year of a multi-country study highlight the extent of the problem. Malar J. 2009:8:299.

75. Williams J, Flood L, Praulins G, Ingham VA, Morgan J, Lees RS, et al. Characterisation of Anopheles strains used for laboratory screening of new vector control products. Parasit Vectors. 2019;12(1):1-14.

76. Tripet F, Touré YT, Taylor CE, Norris DE, Dolo G, Lanzaro GC. DNA analysis of transferred sperm reveals significant levels of gene flow between molecular forms of Anopheles gambiae. Mol Ecol. 2001;10:1725-32.

77. Kyrou K, Hammond AM, Galizi R, Kranjc N, Burt A, Beaghton AK, et al. A CRISPR-Cas9 gene drive targeting doublesex causes complete population suppression in caged Anopheles gambiae mosquitoes. Nat Biotechnol. 2018;36:1062-71.

78. Christophides GK, Zdobnov E, Barillas-Mury C, Birney E, Blandin S, Blass C, et al. Immunity-related genes and gene families in Anopheles gambiae. Science. 2002;298:159-65.

79. Waterhouse RM, Kriventseva EV, Meister S, Xi Z, Alvarez KS, Bartholomay $L C$, et al. Evolutionary dynamics of immune-related genes and pathways in disease-vector mosquitoes. Science. 2007;316:1738-43.

80. Russell TL, Lwetoijera DW, Knols BGJ, Takken W, Killeen GF, Ferguson HM. Linking individual phenotype to density-dependent population growth: the influence of body size on the population dynamics of malaria vectors. Proc R Soc B. 2011;278:3142-51.

81. Seyoum A, Sikaala CH, Chanda J, Chinula D, Ntamatungiro AJ, Hawela $M$, et al. Human exposure to anopheline mosquitoes occurs primarily indoors, even for users of insecticide-treated nets in Luangwa Valley, South-east Zambia. Parasit Vectors. 2012;5:101.

82. Maia MF, Kreppel K, Mbeyela E, Roman D, Mayagaya V, Lobo NF, et al. A crossover study to evaluate the diversion of malaria vectors in a community with incomplete coverage of spatial repellents in the Kilombero Valley, Tanzania. Parasit Vectors. 2016;9(1):1-13.

83. Service MW, Oguamah D. Colonization of Anopheles funestus. Nature. 1958; 181:1225,

84. Nepomichene TN, Andrianaivolambo L, Boyer S, Bourgouin C. Efficient method for establishing F1 progeny from wild populations of Anopheles mosquitoes. Malar J. 2017;16:21.

\section{Publisher's Note}

Springer Nature remains neutral with regard to jurisdictional claims in published maps and institutional affiliations.

Ready to submit your research? Choose BMC and benefit from:

- fast, convenient online submission

- thorough peer review by experienced researchers in your field

- rapid publication on acceptance

- support for research data, including large and complex data types

- gold Open Access which fosters wider collaboration and increased citations

- maximum visibility for your research: over $100 \mathrm{M}$ website views per year

At BMC, research is always in progress.

Learn more biomedcentral.com/submissions 